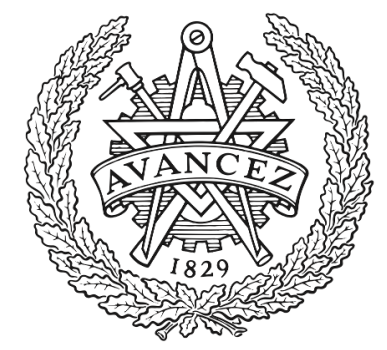

CHALMERS

UNIVERSITY OF TECHNOLOGY

\title{
Severely Corroded Reinforced Concrete with Cover Cracking: Part 2. Anchorage Capacity
}

Downloaded from: https://research.chalmers.se, 2023-04-26 09:32 UTC

Citation for the original published paper (version of record):

Zandi, K., Coronelli, D., Lundgren, K. (2010). Severely Corroded Reinforced Concrete with Cover Cracking: Part 2. Anchorage Capacity. RILEM Bookseries, 5: 207-217

N.B. When citing this work, cite the original published paper. 
Zandi Hanjari, K., Lundgren, K. and Coronelli, D. (2010). Severely corroded reinforced concrete with cover spalling: Part 2. Anchorage capacity. Joint FibRILEM Workshop on Modelling of Corrosion Concrete Structures, 22-23 Nov., Madrid, Spain. 


\title{
Severely Corroded Reinforced Concrete with Cover Cracking: Part 2. Anchorage Capacity
}

\author{
Kamyab Zandi Hanjari ${ }^{1}$, Dario Coronelli ${ }^{2}$, Karin Lundgren ${ }^{1}$ \\ ${ }^{1}$ Chalmers University of Technology, Department of Civil and Environmental \\ Engineering, Sweden \\ ${ }^{2}$ Politecnico di Milano, Dipartimento di Ingegneria Strutturale, Italy
}

\begin{abstract}
There is a growing need for reliable methods of assessing the loadcarrying capacity and remaining service life of corroded structures. In an ongoing research by the authors, issues that have not been investigated in the methods and models available today to calculate the remaining load-carrying capacity of the corroded structures are identified. Two main issues; i.e. high amount of corrosion leading to cover spalling and the effect of corroding stirrups, were investigated in an experimental program. Pull-out tests were carried out on beam-end specimens with long embedment length to study the anchorage capacity of a corroded bar. The specimens were subjected to electrochemical corrosion process leading to different corrosion penetrations prior to mechanical loading. Details concerning electrochemical corrosion setup, corrosion-induced cracking and numerical modelling of a corroding bar are presented in a companion paper subtitled "Part 1. Crack initiation, crack propagation and cover delimitation". Three types of specimens, with stirrups, without stirrups and with corroding stirrups, were subjected to pull-out test. The test results showed a significant influence of stirrups not only on corrosion-induced cracking but also on anchorage capacity and failure mode in the pull-out test. Finally, the corrosion and mechanical testing phases were simulated in a finite element model using the corrosion and bond models earlier developed by Lundgren [1,2]. The outcomes of the numerical modelling help to further understand the effect of high corrosion penetrations and presence of stirrups on failure modes observed in the experiments.
\end{abstract}

\section{Introduction}

When studying the anchorage of a ribbed bar in structural concrete members, the anchorage capacity is strongly influenced by the actual confinement conditions. In general, confinement is a result of the surrounding concrete, stirrups and transverse 
pressure[3]. The corrosion of reinforcement leads to volume expansion of the steel, which generates splitting stresses in the concrete influencing the bond between concrete and reinforcement. For a larger corrosion penetration, the splitting stresses may lead to cover cracking and, finally, spalling of the concrete cover. In the extreme case, when cover spalling occurs, the resisting mechanism in the cross section is altered and stirrups are the main factor providing confinement to the main reinforcement and resulting in residual anchorage capacity.

In earlier works within this field, several models of the corrosion and bond have been developed and implemented in the finite element. In the model by Lundgren $[1,2,4]$, the splitting stresses are introduced and the bond stress depends not only on the slip but also on the normal stress between the reinforcement and the surrounding concrete. In addition the model is capable of taking into account the effects of the transverse pressure. However, the model is only calibrated for the effect of corrosion on the main reinforcement. To the authors' knowledge, there exists no model taking into account the effect of corroded stirrups on cover cracking and cover spalling and to study the anchorage capacity after cover delamination. This is the main aim of the research carried out.

The detailed 3D bond and corrosion model, developed by Lundgren, was used to analyze test specimens with severe corrosion. The type of the specimen was similar to the ones tested by Magnusson [5], in which the specimens had a shape of a beam-end after inclined shear cracking. The details concerning the specimens, electrochemical corrosion and test set-up are presented in a companion paper subtitled "Part 1. Crack Initiation, Crack Propagation and Cover Delamination".

The bond model is a frictional model and the corrosion model takes into account the effect of corrosion of main reinforcement and stirrups as the expansion of the corrosion products. The concrete was modelled using 3D solid elements with a constitutive model based on non-linear fracture mechanics using a rotating crack model based on total strain. Three-dimension solid elements with a constitutive model based on Von Mises yield criterion with associated flow and isotropic hardening were used to model the main reinforcement and stirrups. The results computed by the model were compared with the experiments.

\section{Experimental Setup}

Pull-out tests were carried out on beam-end specimens with long embedment length to investigate the global bond behaviour of an anchored bar when the concrete cover has cracked and spalled off due to corrosion. In total, twenty two beam-end specimens were cast using a concrete grade of $\mathrm{C} 30 / 37$. The concrete was mixed in two batches, with and without $3 \%$ sodium chloride, and cast into beamend moulds of which eleven specimens were made without sodium chloride and eleven were cast with $3 \%$ sodium chloride concrete. Six cylinders and five cubes were also prepared from each concrete batch for compression and splitting tension 
tests. The specimens were kept in a laboratory environment until 28 days after which they were demoulded and kept in a curing room at $20^{\circ} \mathrm{C}$ and $50 \% \mathrm{RH}$. More details are provided in the companion Paper 1.

The specimens had a shape of a beam-end after inclined shear cracking, see Figure 1. For the beam-end specimens, since delamination of concrete cover due to corrosion was desired, a small concrete cover, $1.5 \varnothing$, was used. The influences of the location of the anchored bar, middle and corner placement; the amount of transverse reinforcement; the corrosion level of longitudinal reinforcement, cracked cover and delaminated cover; and corrosion of transverse reinforcement were studied, see Table 1 . The beam-end specimens were cast with the main longitudinal reinforcement of $20 \mathrm{~mm}$ in the horizontal position at the bottom of the moulds, and with the transverse reinforcement of $8 \mathrm{~mm}$. More details of the specimen geometry and reinforcements are given in the companion Paper 1.

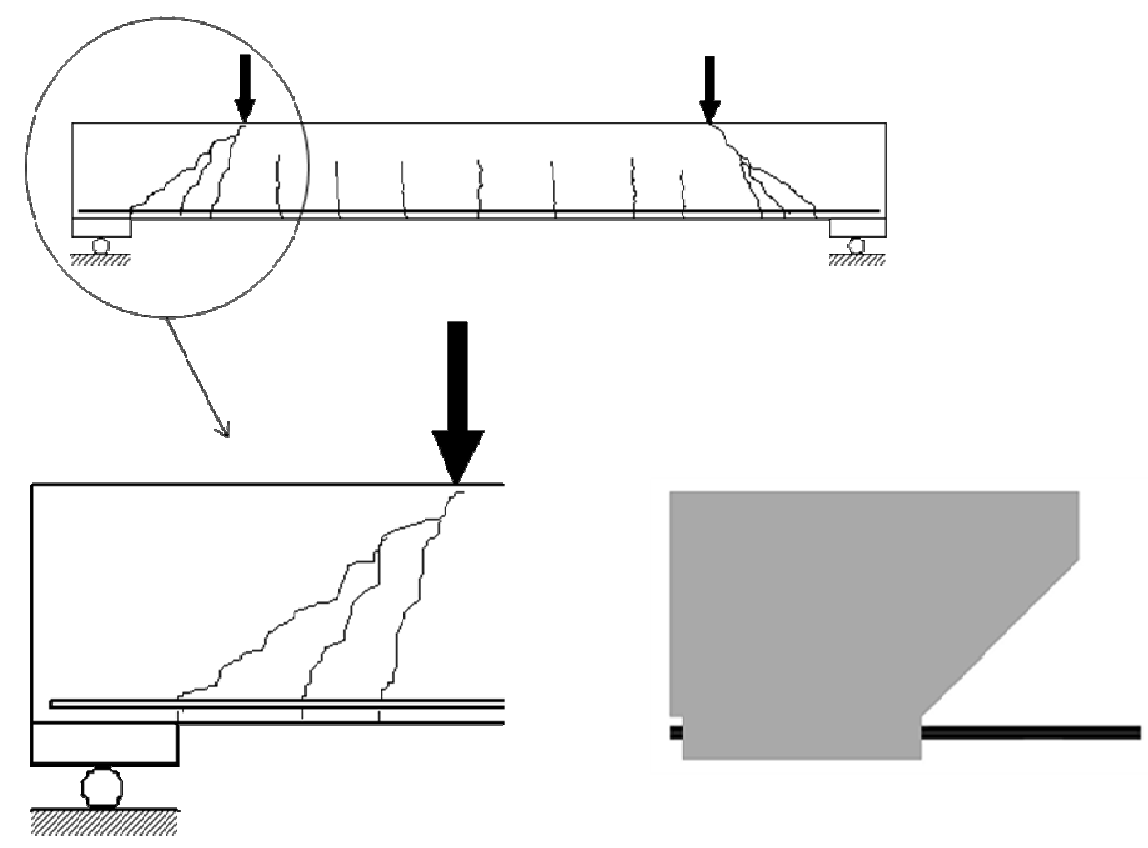

Figure.1 - Schematic illustration of the beam-end specimen.

The test program is summarised in Table 1. Pull-out test was carried out on reference specimens and corroded specimens to different levels:

- Level 1 corresponded to cracks propagating along the main reinforcement; the corrosion level is around $1-2 \%$;

- Level 2 corresponded to a corrosion level of approximately $10 \%$;

- Level 3 aiming to reach the delamination of the covers (tests still on their way). 
Table 1. Test program.

\begin{tabular}{|c|c|c|c|c|}
\hline \multirow[b]{2}{*}{ Specimens } & \multirow[b]{2}{*}{$\begin{array}{l}\text { Position of } \\
\text { tested bar(s) }\end{array}$} & \multicolumn{3}{|c|}{$\mathrm{N}^{\circ}$ of specimens } \\
\hline & & $\begin{array}{l}\text { With non- } \\
\text { corroded } \\
\text { stirrups }^{(1)} \\
\text { (Type A) }\end{array}$ & $\begin{array}{l}\text { Without } \\
\text { stirrups }^{(1)} \\
\text { (Type B) }\end{array}$ & $\begin{array}{c}\text { With } \\
\text { corroded } \\
\text { stirrups }^{(1)} \\
\text { (Type C) }\end{array}$ \\
\hline \multirow{2}{*}{ Reference; $0 \%$ corrosion } & Middle bar & $1,1,1$ & $1,1,1^{*}$ & $x$ \\
\hline & Corner bars & $1,1,1^{*}$ & 1,1 & $x$ \\
\hline \multirow{2}{*}{$\begin{array}{l}\text { Cracks along the main bar; } \\
1-2 \% \text { corrosion }\end{array}$} & Middle bar & 1 & $x$ & $x$ \\
\hline & Corner bars & 1 & $x$ & $x$ \\
\hline \multirow{2}{*}{$\begin{array}{l}\text { Propagation of cracks; } \\
\text { Approx. } 10 \% \text { corrosion }\end{array}$} & Middle bar & $x$ & 1 & $x$ \\
\hline & Corner bars & 1 & 1 & 1 \\
\hline \multirow{2}{*}{$\begin{array}{l}\text { Corrosion leading to cover } \\
\text { delamination }\end{array}$} & Middle bar & $1^{*}, 1^{*}$ & $x$ & $1^{*}$ \\
\hline & Corner bars & $1^{*}$ & $x$ & $1^{*}$ \\
\hline
\end{tabular}

(1) Along the embedment length

* Not subjected to pull-out test yet

The specimens were tested in a test rig specifically designed for these tests. The test-setup is sketched in Figure 2. Deformation control was adopted to permit measurements in the post-peak behaviour. The loading was controlled in the displacement of the active end of the main bar. Initially, the deformation rate was about $0.10 \mathrm{~mm} /$ minute; after the maximum load capacity reached the deformation rate was increased in steps. In each test either the middle bar or the two corner bars of the specimen was subjected to displacement.

The tensile force in the bar was measured using one load cell for each main bar tested; i.e. two load cells in a corner bar test and one in a middle bar test. Instrumentation was provided to measure the relative displacement of the main bars at both the active and passive ends relative to the stable faces of the specimen; see Figure 2.

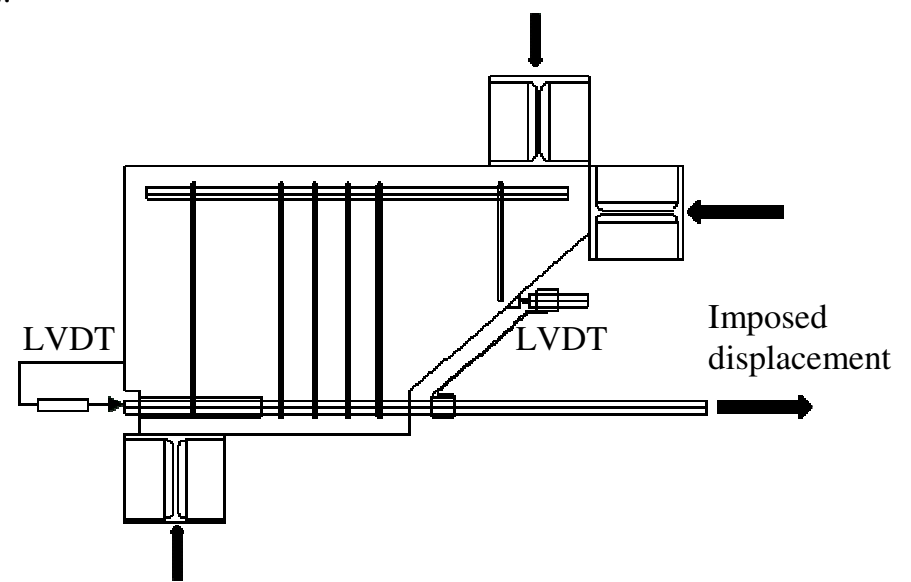

Figure 2. Test setup and instrumentation. 


\section{Numerical modelling}

The beam-end specimens were modelled in detailed 3D finite element (FE) analysis using FE program DIANA; see Figure 3. The analyses were carried out in two phases. In the first phase, the corrosion attack was applied in time steps as the expansion of the corrosion product. In the latter phase, the external load was gradually imposed on the tested bar as prescribed displacement. The principal aspects of the FE model, concrete model, interaction of the concrete and reinforcement (bond model), corrosion model and the material properties are provided in the companion paper subtitled "Paper 1. Crack Initiation, Crack Propagation and Cover Delamination". Here, a short description of the second phase of the analysis simulating the pull-out testing condition is given below.

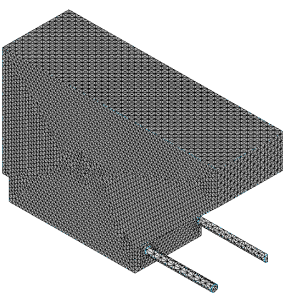

Specimen

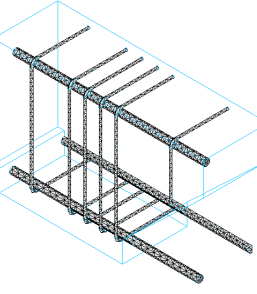

Type A

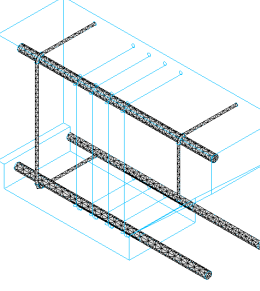

Type B

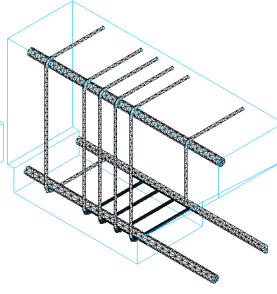

Type C

Figure 3. The FE model for the beam-end specimens.

Due to symmetry, half of the specimen was modelled. The boundary conditions at the supports and the symmetry plane are shown in Figure 4. All the nodes at the symmetry plane were supported for displacement in y-direction. Similar to the experimental setup, the load was imposed on either middle bar or the two corner bars as prescribed displacement.
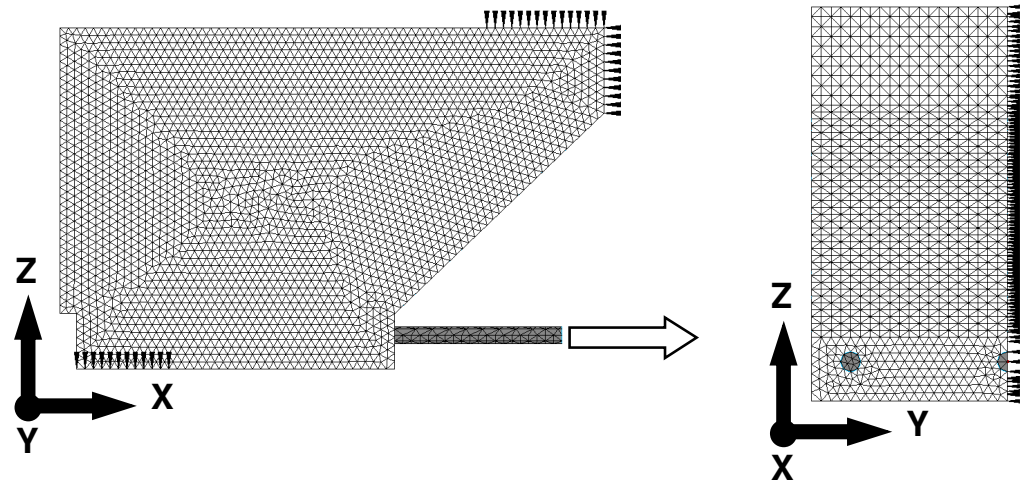

Figure 4. Boundary conditions at supports and symmetry plane. 


\section{Results}

The test results together with the results from numerical modelling are presented and compared here. The results are limited only to specimen types A and B up to the second level of corrosion (about $10 \%$ cross-section loss); specimens with cover spalling and specimens of type $\mathrm{C}$ are still subjected to electrochemical corrosion. An overview of the test results in terms of anchorage capacity normalized with respect to reference specimens versus corrosion attack is presented in Figure 5. The anchorage capacity achieved in the pull-out test of reference specimens without stirrups is roughly $65 \%$ of the capacity observed in specimens with stirrups. For specimens with stirrups, small bond deterioration was observed in spite of rather large corrosion penetration, about 0.4 to $0.5 \mathrm{~mm}$. However, such corrosion caused relatively large bond deterioration in specimens without stirrups, around $50 \%$ reduction in anchorage capacity. This highlights the importance of stirrups as the main source of confinement after corrosion-induced cover cracking. From the results available in this stage of the program, slightly smaller effect of stirrups is seen on anchorage capacity of the middle bar. This is due to the fact that stirrups provide more confinement, at the bend, to the corner bar compared to middle bar. Generally, the bond deterioration observed in the specimens is within the expected range when compared with the test results available in the literature.

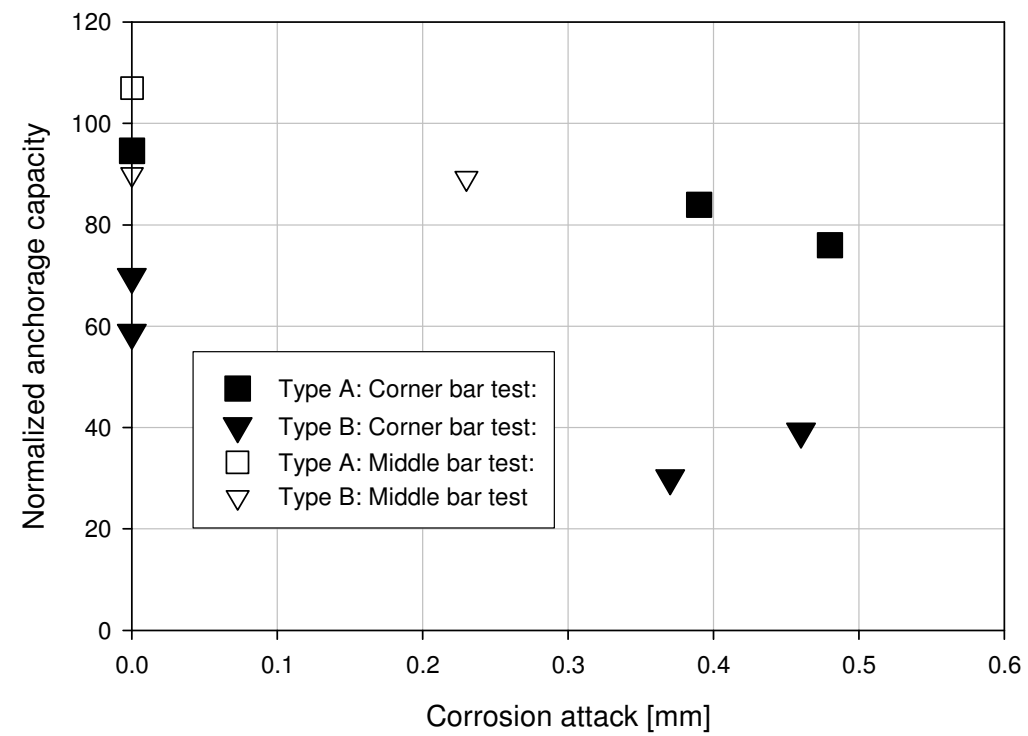

Figure 5. Overview of the test results in terms of anchorage capacity normalized with respect to reference specimens versus corrosion attack. 
In the test carried out on anchorage in corner regions, the two bars were loaded simultaneously. However, as displacement was controlled using two LVDTs, one on each bar, it was possible to register the individual behaviour of the bars. A comparison of the anchorage capacity and the slip at the maximum anchored force is given for test result and numerical modelling in Table 2. The tests showed a significant importance of the bar position; i.e. higher anchorage capacity for middle bars. Depending on the level of corrosion and presence of stirrups, different types of crack patterns at failure were observed: see Figure 6.

(a) Shear: inclined cracking starting from support, developing particularly in specimens with stirrups with low corrosion attack.

(b) Bond shear: cracks running along the bar and turning parallel to inclined side of the "nose", mostly developing in non-corroded specimens.

(c) Bond: splitting cracks parallel to the bar, mainly in corroded specimens.

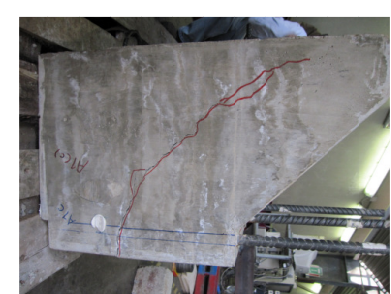

(a)

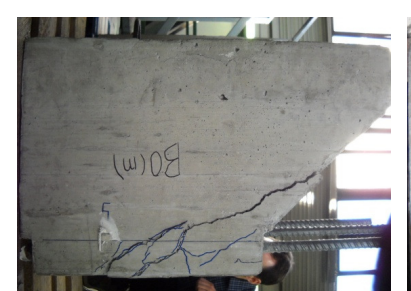

(b)

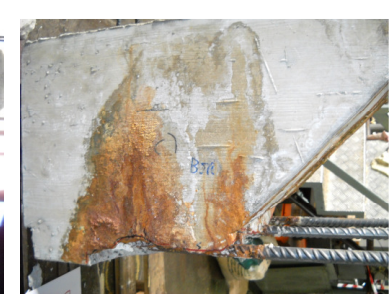

(c)

Figure 6. Different crack patters at failure: (a) shear, (b) bond shear, and (c) bond.

It should be noted that neither in the tests nor in the numerical modelling the longitudinal reinforcement yielded. As far as numerical results are concerned, no yielding of the stirrups took place; $350 \mathrm{MPa}$ was the maximum stress in stirrup observed in the analyses.

Table 2. Experimental and numerical results.

\begin{tabular}{|c|c|c|c|c|c|c|c|}
\hline \multirow[b]{2}{*}{ 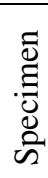 } & \multirow[b]{2}{*}{$\begin{array}{c}\text { Tested } \\
\text { bar }\end{array}$} & \multirow[b]{2}{*}{$\begin{array}{l}\text { Corrosion } \\
\text { condition }\end{array}$} & \multicolumn{2}{|c|}{ Experiment } & \multicolumn{2}{|c|}{ FE modelling } & \multirow[b]{2}{*}{$\begin{array}{c}\text { Crack } \\
\text { pattern } \\
\text { at } \\
\text { failure* }\end{array}$} \\
\hline & & & $\begin{array}{c}\tau_{\max } \\
{[\mathrm{MPa}]}\end{array}$ & $\begin{array}{c}\text { Slip at } \\
\tau_{\max } \\
{[\mathrm{mm}]}\end{array}$ & $\begin{array}{c}\tau_{\max } \\
{[\mathrm{MPa}]}\end{array}$ & $\begin{array}{c}\text { Slip at } \\
\tau_{\max } \\
{[\mathrm{mm}]}\end{array}$ & \\
\hline \multirow{4}{*}{ 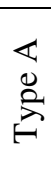 } & \multirow{2}{*}{ Corner } & Reference & 5.05 & 0.36 & 4.80 & 0.12 & BS \\
\hline & & Corroded & 5.52 & 0.13 & 4.23 & 0.06 & BS or $\mathrm{S}$ \\
\hline & \multirow{2}{*}{ Middle } & Reference & 8.11 & 0.17 & 7.60 & 0.32 & $\mathrm{~B}$ \\
\hline & & Corroded & 6.44 & 0.09 & 6.93 & 0.26 & B \\
\hline \multirow{4}{*}{ 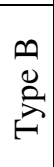 } & \multirow{2}{*}{ Corner } & Reference & 4.34 & 0.08 & 4.42 & 0.12 & BS \\
\hline & & Corroded & 2.64 & 0.02 & 3.18 & 0.03 & $\mathrm{~B}$ \\
\hline & \multirow{2}{*}{ Middle } & Reference & 7.05 & 0.13 & 7.47 & 0.59 & BS \\
\hline & & Corroded & 6.08 & 0.06 & 6.22 & 0.05 & $\mathrm{~B}$ \\
\hline
\end{tabular}

* S: shear, BS: bond shear, and B: bond 
Specimens with non corroded stirrups (Type A)

The crack propagation in non-corroded corner bar test was different from that observed in non-corroded middle bar test. In the corner bar test, the cracking started with the development of a transverse crack at the end of the bonded zone. At a higher load, this crack further propagated and formed a shear crack; this corresponds to the first peak in the bond-slip diagram shown in Figure 7(a). Thereafter, several transverse cracks initiated and inclined toward the loaded end forming a bond shear crack pattern; corresponding to the second peak. Meanwhile, longitudinal cracks initiated from the loaded end stopped when reached the first stirrup. The two peaks in the load were also observed in the numerical modelling. The corroded specimen tested for corner bar showed higher capacity, see Figure 7(b), and different crack pattern at failure in comparison with the reference specimen. This might be due to relatively low amount of corrosion leading to slightly higher bond resistance. In the middle bar test of reference and corroded specimens, the failure occurred when a dominant longitudinal crack and two inclined cracks running to the corner bars formed.

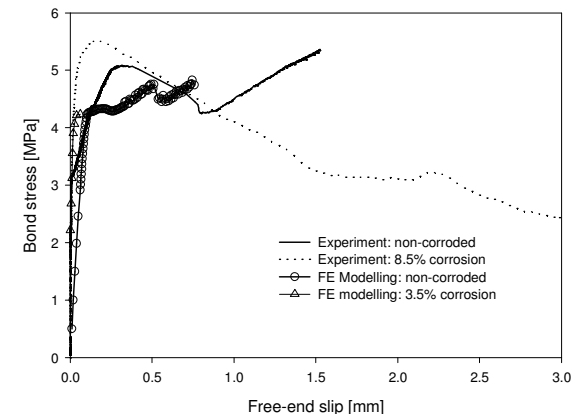

(a)

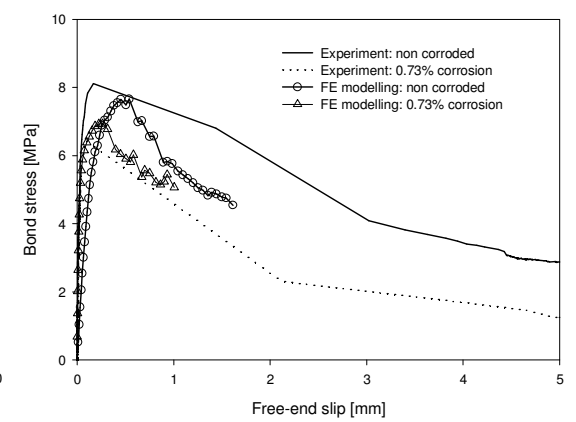

(b)

Figure 7. Bond stress versus free-end slip for (a) corner bar and (b) middle bar test.
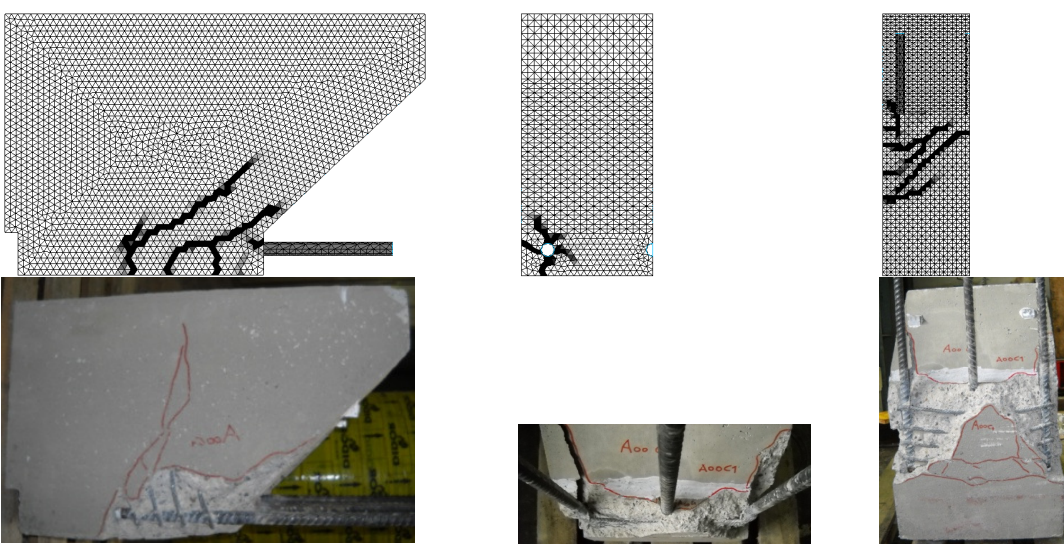

Figure.8 Crack pattern: reference specimen Type A, corner bar test. 


\section{Specimens without stirrups (Type B)}

The crack propagation in non-corroded corner bar test was similar to that observed in non-corroded middle bar test; however it was different from what was seen in specimens with stirrups (Type A). In these specimens, the cracking started with the development of dominant longitudinal crack appeared on the bottom cover all along the bonded length. This was followed by extensive inclined cracking forming a bond shear crack pattern. The corrosion in specimens without stirrups, prior to mechanical loading, led to a wide longitudinal crack along the bonded length. This crack appeared on both bottom and side covers around a corroded bar in corner region. This resembles a corner cover spalling situation, although the corner cover was not completely fallen off as the amount of corrosion was relatively low. These corrosion-induced cracks were widened when pull-out forced was imposed on the bar. The final failure took place with a typical bond (splitting) crack pattern. The bottom cover totally fallen off in a corner bar test; see Figure 10 . This agrees very well with what was seen in the numerical analysis. The deterioration of the capacity is also well estimated by numerical analysis.

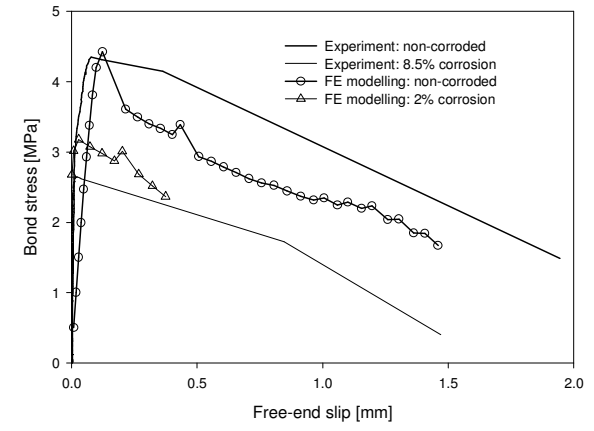

(a)

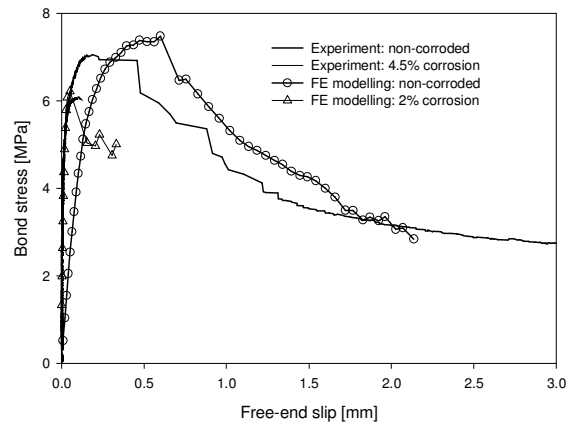

(b)

Figure 9. Bond stress versus free-end slip for (a) corner bar and (b) middle bar test.
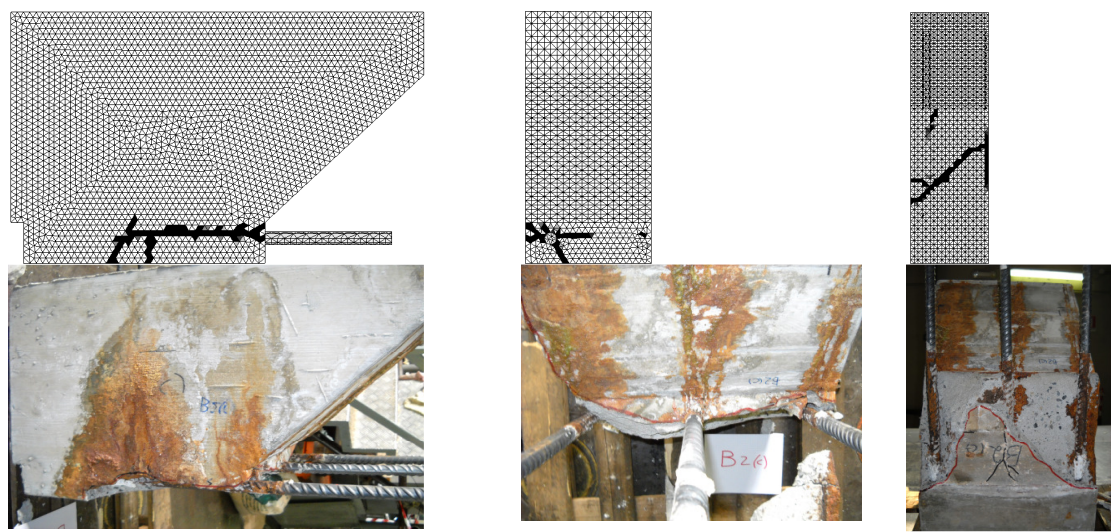

Figure.10 Crack pattern: corroded specimen Type B, corner bars test. 


\section{Conclusion}

In an ongoing research, the effect of high amount of corrosion and presence of transverse reinforcement on anchorage capacity of an anchored bar in a corner and middle position has been studies experimentally and numerically. Beam-end specimens were subjected to electrochemical corrosion process prior to anchorage test. While the results of the corrosion phase are presented in the companion Paper 1 , the anchorage test results together with the numerical simulations are discussed in this paper.

The test results showed a significant effect of the stirrups, position of the tested bar and the effect of corrosion on the anchorage capacity and the failure mode. The result extracted from a 3D model of the specimens and the earlier developed bond and corrosion models, by Lundgren, show a good fracture correspondence both in corrosion phase and in pull-out phase. The outcomes of the numerical modelling are useful to further understand the effect of high corrosion penetration and presence of stirrups on failure modes observed in the experiments.

In the continuation of the presented research work, the effect of corroding stirrups on corrosion-induced cracking and anchorage capacity will be studied. Also higher corrosion levels close to $20 \%$ of the main bars will be analysed. This will be, later on, used for further verification and calibration of the 1D bond model earlier developed by the authors [6].

\section{References}

[1] K. Lundgren, Bond between ribbed bars and concrete. Part 1: Modified model, Magazine of Concrete Research, 57 (7) (2005) 371-382.

[2] K. Lundgren, Bond between ribbed bars and concrete. Part 2: The effect of corrosion, Magazine of Concrete Research, 57 (7) (2005) 383-395.

[3] Fib. Bond of reinforcement in concrete, State-of-art report, Fédération internationale du béton, prepared by Task Group Bond Models, Lausanne fib bulletin 10, 2000.

[4] K. Lundgren, Three-dimensional modelling of bond in reinforced concrete: theoretical model, experiments and applications, Ph.D. Thesis, Department of Structural Engineering / Concrete Structures, Chalmers University of Technology, Göteborg, Sweden, 1999.

[5] J. Magnusson, Bond and Anchorage of Ribbed Bars in High-Strength Concrete, Ph.D. Thesis, Division of Concrete Structures, Chalmers University of Technology, Göteborg, 2000.

[6] K. Lundgren, A. S. S. Roman, H. Schlune, K. Z. Hanjari, P. Kettil, Effects on bond of reinforcement corrosion, International RILEM workshop on Integral Service Life Modeling of Concrete Structures, 5-6 November 2007, Guimaraes, Portugal, 2007, RILEM Publications S.A.R.L, 231-238. 